\title{
Tails Wagging Dogs
}

A funny thing happened on the way to the form. In the past decade, many libraries believed they were developing or using automated systems to produce catalog cards, or order slips, or circulation control records. The trauma of AACR2 implementation has helped many to realize belatedly that they have, in fact, been building data bases.

Libraries must relate their own machine-readable records to each other in a new way as they face new applications. Further methods of relating and using records from different libraries, and even different networks, are becoming necessities in our increasingly interdependent world.

A narrow view of the process of creating records has often resulted in introduction of nonstandard practices that provide the required immediate result, but create garbage in the data base. In effect, letting the tails wag the dogs. For many years, John Kountz and the TESLA (Technical Standards for Library Automation) Committee addressed this issue forcefully, but were as voices in the wilderness.

The problems created are the problems of success. The expectations libraries have developed have outstripped their practices. Many libraries are only now seriously addressing the practices they have used to create data bases that already contain hundreds of thousands of records.

Precisely because of its success, the OCLC system is a useful case in point. In general, OCLC has adhered closely to MARC standards. In call number and holding fields, national standards have been late forthcoming, and libraries have often improvised. Meeting the Procrustean needs of catalog cards has ofttimes blinded libraries to the long-term effects of their practices. Multiple subfield codes to force call number "stacking" and omission of periods from LC call numbers are two examples of card-driven practice.

Not following recommended OCLC practice of fully updating the record at each use has created archive tapes requiring significant manual effort to properly reflect library holdings. Variant branch cataloging practices create dilemmas. Some malpractices have resulted from attempts to beat pricing algorithms. Some, like retaining extraneous fields or accepting default options when they are incorrect, merely reflect laziness or shortsighted procedures.

While implementing systems in the present, libraries must keep a weather eye to the future. What new requirements will future systems place on records being created today?

BRIAN AVENEY 